\title{
THINNER ABUSE ALTERS PEAK OF FREQUENCY OF EEG SPECTRA ANALYSES
}

\author{
Adrián Poblano', Blanca Flores², Carmina Arteaga3, \\ Teodoro Flores 4 , Yolanda Elías 5 , Guadalupe Pineda ${ }^{6}$
}

\begin{abstract}
Study objective: The aim of the investigation was to use electroencephalography (EEG) to study whether long-term thinner abuse may result in the slowing, disorganization and asymmetry of the EEG cortical rhythms. Method: Twenty-two patients attending with antecedent of thinner abuse only, and twenty two controls without alcohol, smoking, and drug abuse in the same age range and gender we re studied. EEG recording were compared by means of the analyses of peak of frequency (POF), frequency of disorganization, and asymmetry of the background activity in patients and controls at rest eyesclosed condition in electrodes P3, P4, 01, and O2. Results: Significant differences in POF among groups was observed in P3 and P4 location showing lower values in thinner abusers, but not in 01 and $\mathrm{O} 2$ locations. Frequencies of disorganization and asymmetry showed significantly higher proportions in thinner abusers. Bivariate correlations among POF at the four electrode location and time of thinner abuse showed significant values. However after partial correlation calculation correcting for age, significant values disappeared. Conclusion: Thus thinner abuse relates with slowing of POF in the EEG of patients with thinner abuse associated with disorganization, and asymmetry depending on time of abuse.
\end{abstract}

KEY WORDS: thinner abuse, toluene exposure, electroencephalography, quantitative electroencephalography.

\section{El abuso de tíner altera el pico de frecuencia del análisis espectral del EEG}

RESUMEN- Objetivo: Utilizar el electroencefalograma (EEG) para estudiar si el abuso o intoxicación crónica por tíner produce lentificación, desorganización y asimetría de la actividad eléctrica cortical. Método: Se estudiaron 22 pacientes con antecedentes de intoxicación crónica por tíner y 22 sujetos sin antecedentes de abuso de tíner, alcohol, cigarro o drogas en el mismo rango de edad y en igual número de acuerdo al género. Se registro el EEG cuantitativo y se compararon: el promedio del pico de frecuencia (PoF), la frecuencia de desorganización de la actividad de fondo y la presencia de asimetría inter-hemisférica en la condición de reposo físico y mental entre las regiones de los electrodos P3, P4, $\mathrm{O} 1$ y O2. Resultados: Se encontraron diferencias significativas en el PoF entre los grupo estudiados en P3 y P4 observándose valo res menores en el grupo con antecedente de intoxicación crónica con tíner, sin embargo estas diferencias no fueron observadas en 01 y 02. La frecuencia de desorganización y de asimetría fue mayor entre los pacientes con antecedente de intoxicación crónica con tíner. Las correlaciones bivariadas entre el PoF en las cuatro localizaciones y el tiempo de consumo de tíner mostraron valores significativos, sin embargo, cuando fueron corregidas por la edad desaparecieron. Conclusión: La intoxicación crónica por tíner se relaciona a una lentificación del PoF del EEG de estos pacientes asociada con desorganización y asimetría que dependen parcialmente del tiempo de consumo.

PALABRAS CLAVE: abuso de tíner, exposición al tolueno, electroencefalografía cuantitativa, electro e ncefalografía.

Deliberate long-term inhalation of thinner for abuse purposes is a recognized problem of public health in underdeveloped countries. Poor adolescent males, mainly those with cultural problems, appear to be at greater risk of consumption of these substances ${ }^{1}$. Toluene is the major component of organic industrial solvents and is thought to cause the neu- rotoxicity seen in solvent abusers ${ }^{2}$. The effect of continuing use is physical impairment in diffe rent organs as liver, brain, heart, muscles, and others ${ }^{3}$. In central $n$ e rvous system, cerebellar degeneration, and cort ical atrophy has been described and may lead to irreversible brain damage ${ }^{4-6}$.

Electroencephalography (EEG) is the recording of

Laboratory of Cognitive Neurophysiology, National Institute of Rehabilitation, Mexico City, Mexico, and Toxicologic Center at Xochimilco, Department of Health, Federal District Government, Mexico City, Mexico: ${ }^{1} \mathrm{MD}, \mathrm{MSc}$, DSc, Neurophysiologist; ${ }^{2} \mathrm{MD}$, Neurophysiologist; ${ }^{3} \mathrm{MD}$, MSc, Audiologist; ${ }^{4} \mathrm{MD}$, Neurologist; ${ }^{\mathrm{M} D}$, Neurophysiologist; ${ }^{6} \mathrm{MD}$, Psychiatrist.

Received 1 June 2006, received in final form 24 July 2006. Accepted 15 September 2006.

Dr. Adrián Poblano - Calzada México-Xochimilco 289 - Col. Arenal Guadalupe, Del. Tlalpan 14389 - Mexico / Mexico. E-mail: drthinner@starmedia.com 
co rtical electric activity in scalp ${ }^{7}$. A case study with a neuropathologic report, showed a slowing of EEG rhythms in one subject with thinner abuse ${ }^{4}$, on the other hand, one toluene-exposed worker had a normal EEG ${ }^{8}$. Thus, no agreement or quantitative measures of EEG in a systematically studied group of patients with thinner abuse, nor comparison with control subjects has been carried out.

In this paper we decide to use the quantitative EEG to study whether cortical neurophysiologic abnormalities results from thinner abuse.

\section{METHOD}

Subjects - Patients for the study were recruited during 1 year consecutively from among those attending the Toxicologic Center at Xochimilco, Mexico, with antecedent of thinner abuse only. We chose those who had a the most adequate nutritional status. All had correct acuities 20/20 or better and normal screening hearing test at 500,1,000 and 2,000 Hertz frequencies. Patients exposed to known factors responsible for other neurological diseases, such as epilepsy, vascular pathologic conditions, motor system alterations, and patients $>50$ years were excluded from the study. Control subjects were selected from neurologically no rmal subjects included in a database at our Laboratory of the same gender and in the same age range. All EEGs were performed on subjects without at least 2 weeks of thinner consumption, pharmacologic treatment or sedation. Inclusion and exclusion criteria were identical as those of the abuser group except for the variable under investigation. Elimination criteria comprised epileptic discharges or electrographic seizures during EEG recording. The study was approved by the Research Committees of the participating institutions, and patients sign informed consent for study participation.

Electroencephalography - EEG was record in a Nicolet EEG1A97 electroencephalograph (Madison, WI, USA). Twenty four-channel records were made in a semi-dark, silent room and with subjects awake in a sitting position with the head supported by the back of a comfortable chair. Gold cup electrodes were applied with electrode cream according to the $10-20$ system $^{9}$. Sites were cleaned using a cotton swab and alcohol. Impedances were $<10$ Kilo-ohms. EEG was recorded from Fp1, F3, C3, P3, O1, Fp2, F4, C4, P4, O2, F7, T3, T5, F8, T4, T6, Fpz, Fz, Cz, Pz, and Oz. Band-pass filters were set between 0.1 and $35 \mathrm{~Hz}$. Speed recording was $30 \mathrm{~mm} / \mathrm{sec}$. Sensitivity was $7 \mu \mathrm{V} / \mathrm{mm}$. EEG recordings were perf o rmed in eye closed, eye open, and after thre e min under hyperventilation conditions. One minute and thirty sec were recorded during each condition free of muscular, eye, respiratory, and body movements, as recommended by International Federation of Clinical Neuro physiology guidelines ${ }^{10}$. EEG signals were stored on hard disk and send to BEAM II equipment (Nicolet, Madison, WI, USA) for computer processing. EEG signal was then subject to Fast Fourier Transform (FFT). Average of absolute and rel- ative power spectrum, and asymmetry analyses, and calculation of peak of frequency (POF) were carried out and presented as a cartographic maps of brain electric activity.

Data analyses - In order to focus specifically on the posterior dominant rhythm and no other rhythms in alpha range such as the mu rhythm over the motor cortex or the phi rhythm in temporal cortex, only four locations (P3, P4, O1, and O2) were included in further analyses. POF was defined as the major robust peak in spectral analyses. Disorg a nization was defined as pres ence of more than one POF in spectral analyses. Asymmetry was defined as a difference of amplitude of $30 \%$ or more in POF on contralateral hemisphereregions in the spectral analyses. POF was compared by one-tailed Student's t test for independent groups. P resence of disorganization and asymmetry was compared by Fisher exact test. Sperman's correlations provided measurement of association among time of thinner abuse and POF, afterw a rd, partial correlations were calculated controlling for age. Level of statistical significance a priori was $\leq 0.05$.

\section{RESULTS}

The group of thinner abuser (TA) comprised 22 patients ( 17 males and 5 females) with an age range from 12-37 years, exposed to solvents between 2 and 21 years, the majority of subjects with irregular time consumption. Controls (C) were 22 subjects (17 males and 5 females) in the same age range. Average of age in TA was $21.55 \pm$ standard deviation (SD) of 5.97 and in C subjects was $21.77 \pm 5.81$ years; comparison between both groups did not showed a significant difference $(p=0.91)$.

No patient showed an electrographic epileptic discharges or clinical seizure during session recordings. Overall, TA group showed lower values in POF than C. Average of POF at four electrode locations a re show in Table 1. Significant differences between $g$ roups was observed in P3 and P4 electrode location $(p=0.009$ and $=0.008$ respectively), showing lower values in TA group (see example in Fig 1). Frequencies of disorganization and asymmetry are show in Table 2. The TA group showed significantly higher pro p ortions of both features than the $C$ group $(p<0.001$, $\mathrm{p}=0.003$ respectively).

Bivariate correlations among POF at the four electrode location and time of thinner abuse are presented in Table 3. All location showed significant correlation with time of thinner abuse (see example in Fig 2). However after partial correlation calculations correcting for age, significant values disappeared and only P3 and P4 locations showed values near of statistically significance values $(-0.408, p=0.066$ and $-0.407, p=0.066$ respectively). 
Table 1. Peak of frequency in thinner abusers and control sub jects.

\begin{tabular}{lccc}
\hline $\begin{array}{l}\text { Electrode } \\
\text { location }\end{array}$ & $\begin{array}{c}\text { Controls } \\
\text { mean } \pm \text { SD }\end{array}$ & $\begin{array}{c}\text { Thinner abusers } \\
\text { mean } \pm \text { SD }\end{array}$ & $p$ \\
\hline P3 & $9.65 \pm 0.47$ & $9.00 \pm 1.66$ & 0.009 \\
P4 & $9.65 \pm 0.47$ & $8.90 \pm 1.73$ & 0.008 \\
O1 & $9.65 \pm 0.47$ & $9.55 \pm 1.09$ & 0.200 \\
O2 & $9.65 \pm 0.47$ & $9.52 \pm 1.07$ & 0.056 \\
\hline
\end{tabular}

Table 2. Frequency of disorganization and asymmetry in thin ner abusers.

\begin{tabular}{lccc}
\hline Variable & Abnormal & Normal & $\mathrm{p}$ \\
\hline Disorganization & 12 & 10 & $<0.001$ \\
Asymmetry & 6 & 16 & 0.003 \\
\hline
\end{tabular}

Table 3. Correlations between peak of frequency and time of thinner consumption in thinner abusers $(n=22)$.

\begin{tabular}{lcccc}
\hline Electrode & P3 & P4 & O1 & O2 \\
\hline$r$ & -0.557 & -0.457 & -0.506 & -0.560 \\
$\mathrm{p}$ & 0.007 & 0.033 & 0.016 & 0.007 \\
\hline
\end{tabular}

\section{DISCUSSION}

Slowing of POF at P3 and P4-but not at $\mathrm{O} 1$ and $\mathrm{O} 2$ locations-in TA when compared with $\mathrm{C}$ subjects we re observed in this research. A higher frequency of disorganization and asymmetry in TA than in C subjects was also observed. The first point confirms the observation perf o rmed in one case of a patient with paper EEG and with a neuropathologic study 4 . The second point to our knowledge is reported here for first time. Thinner abuse results in the diffuse neuronal death and demyelination observed in autopsies $^{3,4}$. Magnetic resonance imaging (MRI) revealed white matter lesions, atrophic dilatation of ventricles and sulci, and thalamic hypointensities ${ }^{11}$. These abnormalities may result in slowing of several neurophysiologic responses, such as pattern-visual evoked potentials ${ }^{12}$, auditory evoked potentials ${ }^{13-15}$, and delay P300 latency in TA patients ${ }^{16}$. In workers occupationally exposed to organic solvents, somatosensory, brainstem auditory and pattern-reversal evoked potentials were frequently abnormal, but authors of the last study claims that somatosensory evoked potentials possessed the most significant difference ${ }^{17}$. Moreover, other electrophysiologic responses may

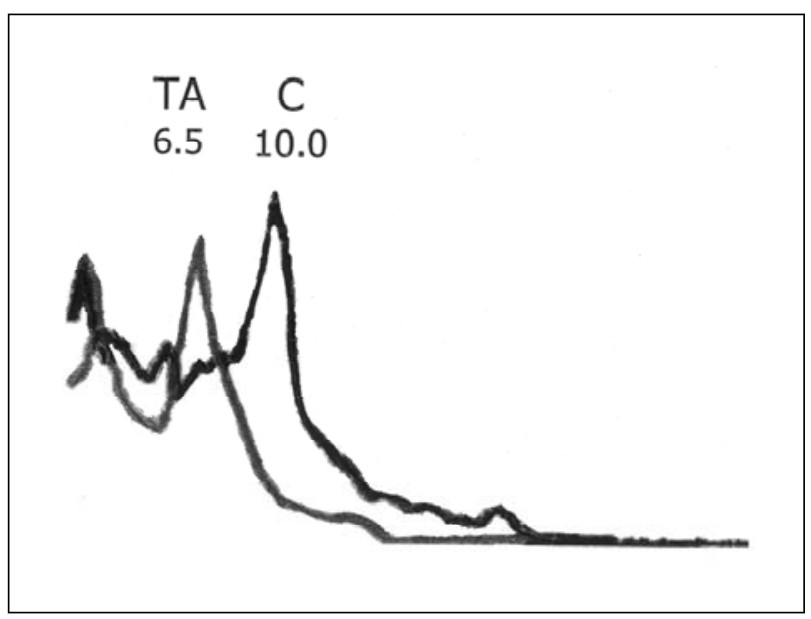

Fig 1. EEG spectra analyses. Comparative EEG spectra analyses for POF determination in one thinner abuser (TA, 6.5 Hertz) and one control (C, $10.0 \mathrm{Hertz}$ ) subjects; TA patient shows slow POF than control subject observed in the horizontal line.

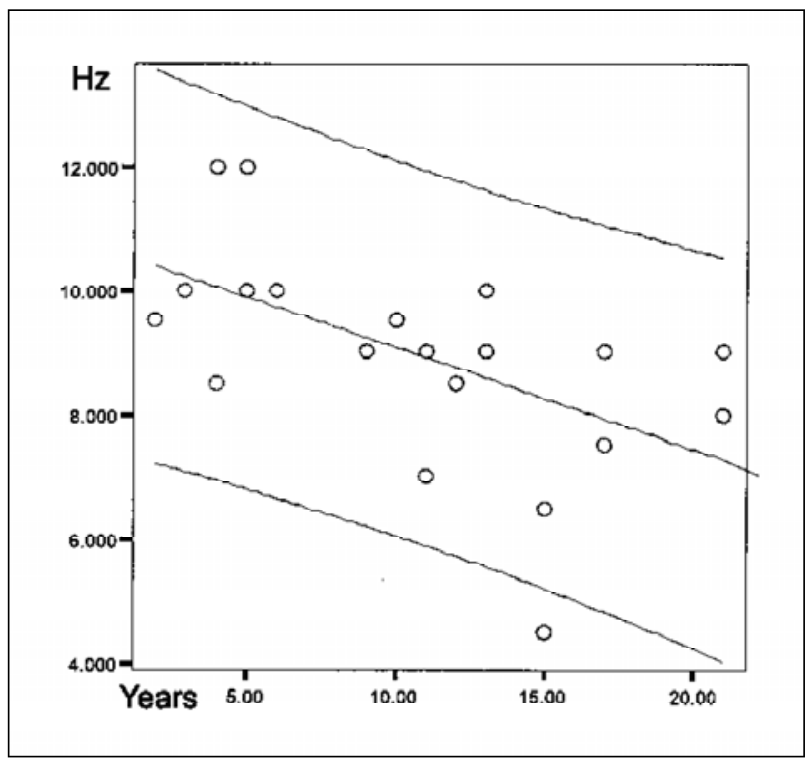

Fig 2. Correlation analyses. Scattergram showing typical cor relation analyses, in this case among POF in P3 location (Hertz, in vertical line) and time of thinner abuse (years, in horizontal line), a negative correlation is evident.

be altered by thinner consumption, such as electronystagmography ${ }^{14,18,19}$.

POF slowing may indicate cerebral blood flow reduction due a correlation between dominant EEG frequency and cerebral oxygen uptake and blood flow reported ${ }^{20}$. Absence of differences on POF in occipital regions can be explained by density of functional connections of networks producing alpha rhythm between thalamic-cortical areas. The higher 
density of connections among thalamic-occipital regions as compared with those of parieto-occipital a reas was observ e $\mathrm{d}^{21}$, this feature can result in higher resistance of the occipital regions. The disorganization re $p$ o rted herein may be the result of corticalsubcortical injury induced by thinner consumption at thalamic-cortical networks. POF asymmetry suggest than one of the cerebral hemispheres is damaged before the other, but this hypotheses requires more research for supporting evidence.

We found a correlation among time of thinner abuse and slowing of POF. A study previously carried out by our work team reported a similar finding in posturographic recordings in TA subjects ${ }^{22}$. Significant correlations disappear when corrected for age; this fact suggest there are other variables that must be taken in consideration in the study of thinner abusetime of thinner abuse relationship. For example Aydin et al. (2002) observed an association between duration of abuse $>4$ years and MRI abnormalities ${ }^{11}$, but Poulsen and Hartvig-Jensen (1986) found no connection between the time of exposure and electronystagmographic changes ${ }^{14}$. These diffe rences may be attributed to variability and irregularity of thinner consumption; in this regard, irregularity of thinner consumption prohibited us from performing correlation analyses among EEG and quantity of thinner consumption. We had several limitations for depend on patient subjective recall of thinner consumption during the clinical interrogatory; thus inconsistent data may have resulted in the statistical analyses. Other variables not weighed in the literature of neurotoxicology of thinner, included influence of patient nutritional status, age and ethnical characteristics which deserve more attention in future studies. Thinner abusers and workers occupationally exposed to solvents can develop diff e rent damage patterns, this fact has not been studied to date and also merits more attention in future works. In summary we found that thinner abuse relates with slowing of EEG in TA patients associated to disorganization, and asymmetry depending on length of time of consumption.

\section{REFERENCES}

1. Committee on Substance Abuse, Committee on Native American Child Health. Abuso de sustancias inhaladas (in Spanish). Pediatrics (Spanish ed.) 1996;41:201-204.

2. Contreras $\mathrm{CM}$, González-Estrada T, Zarabozo D, Fernández-Guardiola A. Pettit and grand mal seizures produced by toluene or benzene intoxication in the cat. Electroencephalogr Clin Neurophysiol 1979;46:290-301.

3. Streicher HZ, Gabow PA, Moss AH, Kono D, Kaehny WD. Syndromes of toluene sniffing in adults. Ann Intern Med 1981;94:758-762.

4. Escobar A, Aruffo C. Chronic thinner intoxication: clinico-pathologic report of a human case. J Neurol Neurosurg Psychiatry 1980;43:986-994.

5. Kornfeld M, Moser AB, Kleinschmidt-de Master BK, Nolte K, Phelps A. Solvent vapor abuse leukoencephalopathy: comparison to adrenoleukoencephalopathy. J Neuropathol Exp Neurol 1994;53:389-398.

6. RosenbergNL, Kleinschmidt-de Masters BK, Davis KA, Dreisbach JN, Hormes JT, Filley CM. Toluene abuse causes diffuse central nervous system white matter changes. Ann Neurol 1988;23:611-614.

7. Lopes da Silva F. Neural mechanisms underlying brain waves: from neural membranes to networks. Electroencephalogr Clin Neurophysiol 1991;79:81-93.

8. Ng TP, Lim LCC, Win KK. An investigation of solvent-induced neuropsychiatric disorder in spray painters. Ann Acad Med 1992;21:797-803.

9. Jaspers $H$. The ten-twenty electrodes system of the international federation. Electroencephalogr Clin Neurophysiol 1958;10:371-375.

10. Nuwer MR, Lehman D, Lopes da Silva F, Matsuoka S, Sutherling W, Vibert JF. IFCN guidelines for topographic and frequency analysis of EEG and EPs: report of an IFCN commitee. Electroencephalogr Clin Neurophysiol 1994;91:1-5

11. Aydin K, Sencer S, Demir T, Ogel K, Tunaci A, Minareci O. Cranial MR findings in chronic toluene abuse by inhalation. AJNR 2002;23:11731179.

12. Poblano A, Lope-Huerta M, Martínez JM, Falcón HD. Pattern-visual evoked potentials in thinner abusers. Arch Med Res 1996;27:531-533.

13. Metrick SA, Brenner RP. Abnormal brainstem auditory evoked potentials in chronic paint sniffers. Ann Neurol 1982;12:553-556.

14. Poulsen P, Hartvig-Jensen J. Brain-stem response audiometry and electronystagmographic findings in chronic toxic encephalopathy (chronic painter's syndrome). J Laryngol Otol 1986;100:155-156.

15. Lope-Huerta M, Poblano A, Martínez JM, Falcón HD. Brainstem auditory evoked potentials in addicts to inhalation of organic solvents (in Spanish). Rev Invest Clin 1996;48:369-372.

16. Morrow LA, Steinhauser SR, Hodgson MJ. Delay in P300 latency in patients with organic solvent exposure. Arch Neurol 1992;49:315-320.

17. Lille F, Margules S, Mallet A, Deschamps D, Garnier R, Dally S. Evoked potentials in workers occupationally exposed to organic solvents. Electromyogr Clin Neurophysiol 1993;33:279-283.

18. Mass EF, Ashe J, Spiegel BA, Zee DS, Leight RJ. Acquired pendular nystagmus in toluene adicction. Neurology 1991;41:282-285.

19. Poblano A, Ishiwara K, Ortega P, Mora L, Pineda G, Arriaga E. Thinner abuse alters optokinetic nystagmus parameters. A rch Med Res 2000; 31:182-185.

20. Ingvar DH, Sjölund B, Ardö A. Correlation between dominant EEG frequency, cerebral oxygen uptake and blood flow. Electroencephalogr Clin Neurophysiol 1976;41:268-276.

21. Feige B, Scheffler K, Esposito F, di Salle F, Henning J, Seifritz E. Cortical and subcortical correlates of electroencephalographic alpharhythm modulation. J Neurophysiol 2005;93:2864-2872.

22. Ishiwara-NiembroK,Poblano-Luna A, Pineda-Hernández G, OrtegaHernández P. Posturographic alterations in thinner abusers. Rev Neurol 2002;35:625-627. 